\title{
Editorial
}

\section{Vannevar Bush: uma apresentação}

Carlos Henrique Brito Cruz

\section{A web e a internet imaginadas em 1945}

Em julho de 1945 uma das pessoas mais bem posicionadas do mundo para especular sobre o futuro da ciência e da tecnologia era Vannevar Bush, que durante os anos anteriores havia dirigido o Escritório de Pesquisa Científica e Desenvolvimento, ligado à Presidência dos EUA. Como diretor, Bush supervisionou e esteve em contato direto e intenso com os principais projetos científicos dos Estados Unidos na Segunda Guerra Mundial, incluindo-se entre estes os dois mais visíveis, que foramo desenvolvimento do radar e a bomba atômica.

Ao final da guerra, Bush definiu a estruturação do sistema de pesquisa norte-americano, com o relatório ao Presidente Truman intitulado "Ciência a fronteira sem fim" que teve - e ainda tem - enorme impacto sobre a organização da atividade científica em muitos outros países, inclusive no Brasil.

Um texto de sua autoria menos conhecido é o que aqui se apresenta, sob o título "As we may think" no qual especula sobre o que a ciência e a tecnologia poderiam trazer à humanidade nos tempos de paz, depois do que havia sido feito durante a guerra. $\mathrm{O}$ foco escolhido foi como os avanços da pesquisa poderiam vir a modificar a forma de se pensar e organizar o conhecimento.

Sua atenção se dirige aos instrumentos de registro e transmissão de informação, que ele considera estarem entre os principais desafios para os cientistas - como ler e entender tantos artigos e relatórios e acessar tantas informações e ali selecionar o que é relevante. Os instrumentos aos quais estava acostumado eram papel, lápis e fichários. 
Indo adiante, Bush analisa como o modo de pensarmos poderia vir a ser alterado se pudéssemos ter acesso à enorme massa de informações criada pela humanidade, e realizar conexões entre elas. Este aparato ele denomina "memex", no qual um indivíduo poderá armazenar todos os livros, registros e comunicações os quais, uma vez indexados, poderão ser consultados de forma automática. Adicionalmente, o interessado poderá criar conexões entre itens pertinentes, e de um ser remetido ao outro.

Quase 45 anos depois, em 1989, Tim Berners-Lee, um físico inglês trabalhando no CERN, deu vida e forma à ideia de Bush, criando a linguagem de programação HTML (hyper text mark up language) e os hyperlinks que hoje todos usam correntemente na web. Antes de Tim, Theodore Nelson havia criado em 1965 o termo hipertexto, para designar "um texto não sequencial, no qual o leitor não fica restrito a uma sequência particular, mas pode seguir conexões (links) e chegar ao documento original a partir de uma citação curta" (esta definição da criação de Nelson é a usada por Tim Berners-Lee em seu livro sobre a criação da web, "Weaving the Web", de 1999).

O artigo aqui traduzido é o que apareceu na Atlantic Monthly em julho de 1945. Uma versão mais curta apareceu em setembro de 1945 na Life, incluindo ilustrações de como seria o "memex".

A ideia do "memex" influenciou Douglas Engelbart, ${ }^{1}$ um dos pioneiros da computação pessoal e da computação orientada a objetos (o sistema que hoje usamos, no qual em vez de o usuário emitir comandos escritos em linguagem de programação ele ativa comandos clicando com um mouse em ícones na tela). Engelbart criou a ideia do mouse e participou da criação da ARPANET, uma rede de computadores precursora da Internet, ambos relacionados a seu projeto apoiado pela Agência de Projetos de Pesquisa Avançados (ARPA) do Departamento de Defesa dos EUA no início dos anos 1960 . O projeto objetivava desenvolver as bases para uma "inteligência aumentada", ou seja, o aumento da capacidade intelectual por meio da interação entre o ser humano e o computador. ${ }^{2}$

1. Há mais sobre isso inclusive um facsimile da cópia de "As we may think" de Douglas Engelbart com anotações feitas por ele nas margens no hyperlink http://dougengelbart.org/events/ vannevar-bush-symposium.html\#2.

2. Uma completa história destes acontecimentos está em What the Dormouse Said: How the Sixties Counterculture Shaped the Personal Computer Industry por John Markoff (Penguin, 2005) que narra as conexões entre a criação do computador pessoal e a contracultura e o movimento hippie nos anos 1960. (Quem gosta de rock and roll clássico logo notará que o título do livro faz referência à música White Rabbit do Jefferson Airplane, a qual cita o coelho de Alice no País das Maravilhas). 
Parece-me mais impressionante que Bush tenha imaginado ser possível fazer o tal Memex do que imaginá-lo e desejá-lo. A ideia de fazer conexões entre coisas aparentemente díspares me parece ser tão antiga quanto o pensamento humano. Afinal, quando Eratóstenes, dois séculos antes de Cristo, idealizou o experimento com o qual mediu o raio da Terra ele fez exatamente isso: conectou informações que para outros pareciam desconectadas. Sendo o Bibliotecário Chefe de Alexandria ele estava em posição especialmente favorável para reunir o conhecimento de que havia um certo poço em Siena (hoje Assuã) no qual em um certo dia do ano se via o sol perfeitamente refletido na água do fundo e portanto o Sol estaria exatamente iluminando verticalmente o poço) e idealizou medir a sombra de uma haste de madeira em uma outra cidade no mesmo horário de tal modo que sabendo a distância entre as cidades pôde demonstrar que a Terra era redonda e estimar seu raio. Muitos séculos depois, quando Adam Smith descreveu os filósofos da Natureza ou homens de especulação como "philosophers or men of speculation, whose trade it is not to do anything, but to observe everything; and who, upon that account, are often capable of combining together the powers of the most distant and dissimilar objects", ele falava exatamente disso: de conectar o desconectado e com isso criar novas ideias. Os enciclopedistas pensavam em reunir todo o conhecimento e, em geral, terminaram derrotados pelo tamanho da tarefa e pela incapacidade de atualizar e de facilitar as conexões entre os inúmeros tópicos. Até porque na maior parte das vezes a conexão tem origem subjetiva resultando da história de experiências de cada indivíduo.

Por tudo isso, "As we may think", de Vannevar Bush é um texto atraente. Pelo momento em que foi escrito, pelo que desejava e esperava do progresso da ciência e da tecnologia e porque parte do que ali se esperava, materializada hoje nos hyperlinks na internet e na web, passou a afetar tão intensamente nossas vidas.

\section{Carlos Henrique Brito Cruz}

Professor no Instituto de Física Gleb Wataghin da Universidade Estadual de Campinas Unicamp (Campinas, SP, Brasil); Engenheiro Eletrônico pelo Instituto Tecnológico da Aeronáutica - ITA (São José dos Campos, SP, Brasil); Mestre e doutor em Ciências pelo Instituto de Física Gleb Wataghin da Unicamp; diretor do Instituto de Física Gleb Wataghin (1991-1994 e 1998 -2002); Pró-reitor de Pesquisa da Unicamp (1994-1998); Reitor da Unicamp de abril de 2002 a abril de 2005; Presidente da Fundação de Amparo a Pesquisa do Estado de São Paulo FAPESP (São Paulo, SP, Brasil), de 1996 a 2002; membro da Academia Brasileira de Ciências (Rio de Janeiro, RJ, Brasil), desde 2000; diretor científico da Fapesp desde abril de 2005.

Diretoria Científica - Fapesp

Rua Pio XI, 1500 - Alto da Lapa

05468-901 São Paulo, SP, Brasil 